\title{
Capacitance based Reliability Indices of a Real Time Radial Distribution Feeder
}

\author{
${ }^{1}$ D. Murali, ${ }^{2}$ Mr.A.Hema sekhar \\ ${ }^{I} P G$ Student (EPS) Department of EEE Sri Venkatesa Perumal College of Engg \& Tech, puttur \\ ${ }^{2}$ Associate Professor \& HOD Department of EEE Sri Venkatesa Perumal College of Eng. \& Tech,Puttur
}

\begin{abstract}
Assessment of customer power supply reliability is an important part of distribution system operation and planning. Distribution system reliability assessment is a measure of continuity and quality of power supply to the consumers, which mainly depends on interruption profile, based on system topology and component reliability data. The paper mainly describes about the radial Distribution system reliability is evaluated in two methods. One by placing capacitor at weak voltage nodes for improvement of voltage profiles, reducing the total losses. Second way by improving reliability indices by placing protective equipment (isolators) in the feeder. This paper present an effective approach for real time evaluation of distribution power flow solutions with an objective of determining the voltage profiles and total losses. To improve the voltage profiles and reducing losses by placing capacitors at weak voltage profile nodes using Particle Swarm Optimization (PSO) technique. The Distribution System Reliability Indices are also calculated for the existing radial distribution system before and after placement of isolator. In this paper we have considered the load diversity factor for analysis of load data for real time system. Two matrices the bus-injection to branch-current matrix (BIBC), the branch-current to bus voltage matrix $(B C B V)$ and a simple matrix multiplication are used to obtain power flow solutions. This paper also presents an approach that determines optimal location and size of capacitors on existing radial distribution systems to improve the voltage profiles and reduce the active power loss. The performance of the method was investigated on an $11 \mathrm{kV}$ real time Upadyayanagar radial distribution feeder as system of case study. A matlab program was developed and results are presented.
\end{abstract}

Keywords: BIBC, BCBV, Diversity Factor, BVSI, Reliability Indices, Distribution Load Flows, PSO.

\section{Introduction}

The demand for electrical energy is ever increasing. Today over $21 \%$ (theft apart!!) of the total electrical energy generated in India is lost in Transmission (5-7\%) and Distribution (15-18\%). The electrical power deficit in the country is currently about 35\%.Clearly, reduction in losses can reduce this deficit significantly. It is possible to bring down the distribution losses to $6-8 \%$ level in India with the help of newer technological options (including information technology) in the Electrical Power Distribution Sector which will enable better monitoring and control.

The electric utility system is usually divided into three subsystems which are Generation, Transmission, and Distribution. A fourth division, which sometimes made is Sub-Transmission. Electricity distribution is the final stage in the delivery of electricity to end users. A Distribution Network carries electricity from the transmission system and delivers it to consumers. Typically, the network would include mediumvoltage $(<50 \mathrm{kV})$ power lines, electrical substations and pole-mounted transformers, low-voltage (less than 1000 $\mathrm{V})$ distribution wiring and sometimes electricity meters. Electric power is normally generated at $11-25 \mathrm{kV}$ in a power station. To transmit over long distances, it is then stepped-up to $400 \mathrm{kV}, 220 \mathrm{kV}$ or $132 \mathrm{kV}$ as necessary. Power is carried through a transmission network of high voltage lines. Usually, these lines run into hundreds of kilometers and deliver the power into a common power pool called the grid. The grid is connected to load centers through a sub-transmission network of normally $33 \mathrm{kV}$ (or sometimes $66 \mathrm{kV}$ ) lines. These lines terminate into a $33 \mathrm{kV}$ (or $66 \mathrm{kV}$ ) substation, where the voltage is stepped-down to $11 \mathrm{kV}$ for power distribution to load points through a distribution network of lines at $11 \mathrm{kV}$ and lower. The power network, which generally concerns the common man is the distribution network of $11 \mathrm{kV}$ lines or feeders downstream of the $33 \mathrm{kV}$ substation. Each $11 \mathrm{kV}$ feeder which emanates from the $33 \mathrm{kV}$ substation branches further into several subsidiary $11 \mathrm{kV}$ feeders to carry power close to the load points (localities, industrial areas, villages,etc.,). At these load points, a transformer further reduces the voltage from $11 \mathrm{kV}$ to $415 \mathrm{~V}$ to provide the last mile connection through $415 \mathrm{~V}$ feeders (Low Tension (LT) feeders) to individual customers, either at $240 \mathrm{~V}$ (as $1 \mathrm{ph}$. supply) or at $415 \mathrm{~V}$ (as $3 \mathrm{ph}$. supply).A feeder could be either an overhead line or an underground cable. In urban areas, owing to the density of customers, the length of an $11 \mathrm{kV}$ feeder is generally up to $3 \mathrm{~km}$. On the other hand, in rural areas, the feeder length is much larger (up to $20 \mathrm{~km}$ ). A $415 \mathrm{~V}$ feeder should normally be restricted to about $0.5-1.0 \mathrm{~km}$ unduly long feeder's lead to low voltage at the consumer end. 


\section{Diversity Factor}

The probability that a particular piece of equipment will come on at the time of the facility's peak load. It is the ratio of the sum of the individual non-coincident maximum demands of various subdivisions of the system to the maximum demand of the complete system[6]. The diversity factor is always greater than 1 . The (unofficial) term diversity, as distinguished from diversity factor refers to the percent of time available that a machine, piece of equipment, or facility has its maximum or nominal load or demand (a $70 \%$ diversity means that the device in question operates at its nominal or maximum load level $70 \%$ of the time that it is connected and turned on). This diversity factor is used to estimate the load of a particular node in the system.

\section{Load Flow Studies}

The load-flow study in a power system has great importance because it is the only system which shows the electrical performance and power flow of the system operating under steady state [1-3]. A load-flow study calculates the voltage drop on each feeder, the voltage at each bus, and the power flow in all branch and feeder circuits. Losses in each branch and total system power losses are also calculated. Load-Flow studies are used to determine the remain within specified limits, under various contingency conditions only. Load-flow studies are often used to identify the need for additional Generation, Capacitive/Inductive VAR support or the placement of capacitors and/or reactors to maintain system voltages within specified limits. An efficient load-flow study plays vital role during planning of the system and also for the stability analysis of the system. Usually the distribution networks are ill-conditioned in nature. Therefore, the variables for the load-flow analysis of distribution systems are different from those of transmission systems. Many modified versions of the conventional load-flow methods have been suggested for solving power networks with high R/X ratio. The following are the effective load flow techniques used in the distribution networks are Single-Line Equivalent Method, Very Fast Decoupled Method, Ladder Technique, Power Summation Method, Backward and Forward Sweeping Method. The proposed algorithm is tested on a Real Time system.

\section{Formulation of Load Flow Model}

(a) Algorithm Development:

The technique is based on two matrices, the bus-injection to branch-current matrix and the branch current to bus-voltage matrix, and equivalent current injections. In this section, the development procedure will be described to develop BCBV and BIBC for radial distribution feeder. For bus, the complex load S is expressed by

$$
\mathrm{S}_{\mathrm{i}}=\mathrm{P}_{\mathrm{i}}+\mathrm{jQ} \mathrm{Q}_{\mathrm{i}}
$$

Where $\mathrm{i}=1,2, \ldots \mathrm{N}$

And the corresponding equivalent current injection at the $\mathrm{k}^{\text {th }}$ iteration of solution is

$\mathrm{I}_{\mathrm{i}}^{\mathrm{k}}=\left(\mathrm{P}_{\mathrm{i}}+\mathrm{jQ} \mathrm{Q}_{\mathrm{i}} / \mathrm{V}_{\mathrm{i}}^{\mathrm{k}}\right)^{*}$

Where $\mathrm{Vi}^{\mathrm{k}}$ and $\mathrm{Ii}^{\mathrm{k}}$ are the bus voltages and equivalent current injection of bus $\mathrm{i}$ at kth iteration respectively.

\section{(b) Relationship Matrix Development}

A simple distribution network shown in figure 1 is used to find the current equations are obtained from the equation (2). The relationship between bus currents and branch currents can be obtained by applying Kirchhoff's current law (KCL) to the distribution network. Using the algorithm of finding the nodes beyond all branches proposed by Gosh et al. The branch currents then are formulated as functions of equivalent current injections for example branch currents $\mathrm{B} 1, \mathrm{~B}_{3}$ and $\mathrm{B}_{5}$ can be expressed as

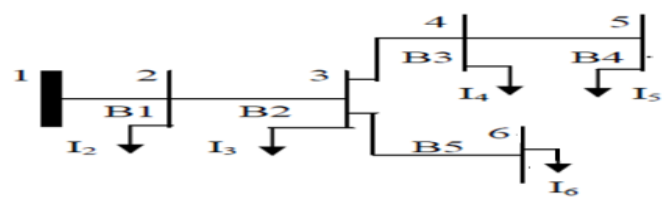

Figure 1. Simple distribution system

$\mathrm{B}_{1}=\mathrm{I}_{2}+\mathrm{I}_{3}+\mathrm{I}_{4}+\mathrm{I}_{5}+\mathrm{I}_{6}$

$\mathrm{B}_{3}=\mathrm{I}_{4}+\mathrm{I}_{5}$

\}

$\mathrm{B}_{5}=\mathrm{I}_{6}$

Therefore the relationship between the bus current injections and branch currents can be expressed as

$$
\left[\begin{array}{l}
B_{1} \\
B_{2} \\
B_{3} \\
B_{4} \\
B_{5}
\end{array}\right]=\left[\begin{array}{lllll}
1 & 1 & 1 & 1 & 1 \\
0 & 1 & 1 & 1 & 1 \\
0 & 0 & 1 & 1 & 1 \\
0 & 0 & 0 & 1 & 0 \\
0 & 0 & 0 & 0 & 1
\end{array}\right]\left[\begin{array}{l}
I_{2} \\
I_{3} \\
I_{4} \\
I_{5} \\
I_{5}
\end{array}\right]----(4 a)
$$


Eq (4a) can be expressed in general form as

$[\mathrm{B}]=[\mathrm{BIBC}][\mathrm{I}]$

The constant BIBC matrix is an upper triangular matrix and contains values of 0 and 1 only. The relationship between branch currents and bus voltages as shown in Fig. 1. For example, the voltages of bus 2, 3, and 4 are

$\mathrm{V}_{2}=\mathrm{V}_{1}-\mathrm{B}_{1} \mathrm{Z}_{12}$

$\mathrm{V}_{3}=\mathrm{V}_{2}-\mathrm{B}_{2} \mathrm{Z}_{23}$

$\mathrm{V}_{4}=\mathrm{V}_{3}-\mathrm{B}_{3} \mathrm{Z}_{34}$

where $V_{i}$ is the voltage of bus $i$, and $Z_{i j}$ is the line impedance between bus $i$ and bus $j$. Substituting (5a) and $(5 \mathrm{~b})$ into $(5 \mathrm{c}),(5 \mathrm{c})$ can be rewritten as

$\mathrm{V}_{4}=\mathrm{V}_{1}-\mathrm{B}_{1} \mathrm{Z}_{12}-\mathrm{B}_{2} \mathrm{Z}_{23}-\mathrm{B}_{3} \mathrm{Z}_{34}$

$\left[\begin{array}{l}V_{1} \\ V_{1} \\ V_{1} \\ V_{1} \\ V_{1}\end{array}\right]-\left[\begin{array}{l}V_{2} \\ V_{3} \\ V_{4} \\ V_{5} \\ V_{6}\end{array}\right]=\left[\begin{array}{ccccc}Z_{12} & 0 & 0 & 0 & 0 \\ Z_{12} & Z_{23} & 0 & 0 & 0 \\ Z_{12} & Z_{23} & Z_{34} & 0 & 0 \\ Z_{12} & Z_{23} & Z_{34} & Z_{45} & 0 \\ Z_{12} & Z_{23} & 0 & 0 & Z_{56}\end{array}\right]\left[\begin{array}{l}B_{1} \\ B_{2} \\ B_{3} \\ B_{5} \\ B_{6}\end{array}\right]--(7 a)$

From (6), it can be seen that the bus voltage can be expressed as a function of branch currents, line parameters, and the substation voltage. Similar procedures can be performed on other buses, therefore, the relationship between branch currents and bus voltages can be expressed as

$[\Delta \mathrm{V}]=[\mathrm{BCBV}][\mathrm{B}]$

Where $\mathrm{BCBV}$ is the branch -current to bus voltage matrix.

(C) Building Formulation Development:

Observing (4), a building algorithm for BIBC matrix can be developed as follows:

Step 1: For a distribution system with $m$-branch section and $n$ bus, The dimension of the BIBC matrix is $m \times(n-$ 1).

Step 2: If a line section (B) is located between bus $i$ and bus $j$, copy the column of the $\mathrm{I}^{\text {th }}$ bus of the BIBC matrix to the column of the $\mathrm{j}^{\text {th }}$ bus and fill a 1 to the position of the $\mathrm{k}^{\text {th }}$ row and the $\mathrm{j}^{\text {th }}$ bus column.

Step 3: Repeat Step (2) until all line sections is included in the BIBC matrix. From equation (7a and $7 \mathrm{~b})$, a building algorithm for BCBV matrix can be developed as follows.

Step 4: For a distribution system with $\mathrm{m}$-branch section and $\mathrm{n}-\mathrm{k}$ bus, the dimension of the BCBV matrix is $\mathrm{m} \mathrm{x}$ $(n-1)$.

Step 5: If a line section is located between bus $i$ and bus $j$, copy the row of the $i^{\text {th }}$ bus of the BCBV matrix to the row of the $\mathrm{j}^{\text {th }}$ bus and fill the line impedance $(\mathrm{Z})$ to the position of the $\mathrm{j}^{\text {th }}$ bus row and the $\mathrm{k}^{\text {th }}$ column.

Step 6: Repeat procedure (5) until all line sections is included in the BCBV matrix. The algorithm can easily be expanded to a multi phase line section or bus.

D. Solution Technique Developments:

The BIBC and BCBV matrices are developed based on the topological structure of distribution systems. The BIBC matrix represents the relationship between bus current injections and branch currents. The corresponding variations at branch currents, generated by the variations at bus current injections, can be calculated directly by the BIBC matrix. The BCBV matrix represents the relationship between branch currents and bus voltages. The corresponding variations at bus voltages, generated by the variations at branch currents, can be calculated directly by the BCBV matrix. Combining (4b) and (7a), the relationship between bus current injections and bus voltages can be expressed as
$[\Delta \mathrm{V}]=[\mathrm{BCBV}][\mathrm{BIBC}][\mathrm{I}]=[\mathrm{DLF}][\mathrm{I}]$
$\mathrm{I}_{\mathrm{i}}^{\mathrm{k}}=\mathrm{I}_{\mathrm{i}}^{\mathrm{r}}\left(\mathrm{V}_{\mathrm{i}}^{\mathrm{k}}\right)+\mathrm{jI}_{\mathrm{i}}^{\mathrm{i}}\left(\mathrm{V}_{\mathrm{i}}^{\mathrm{k}}\right)=\left(\left(\mathrm{P}_{\mathrm{i}}+\mathrm{jQ} \mathrm{Q}_{\mathrm{i}}\right) / \mathrm{V}_{\mathrm{i}}^{\mathrm{k}}\right)^{*}$ $\left[\Delta \mathrm{V}^{\mathrm{k}+1}\right]=[\mathrm{DLF}]\left[\mathrm{I}^{\mathrm{k}}\right]$
$\left[\mathrm{V}^{\mathrm{k}+1}\right]=\left[\mathrm{V}^{\circ}\right]+\left[\Delta \mathrm{V}^{\mathrm{k}+1}\right]$

And the solution for distribution power flow can be obtained by solving iteratively. According to the research, the arithmetic operation number of $\mathrm{LU}$ factorization is approximately proportional to $\mathrm{N}^{3}$. For a large value of $\mathrm{N}$, the LU factorization will occupy a large portion of the computational time. Therefore, if the LU factorization can be avoided, the power flow method can save tremendous computational resource. From the solution techniques described before, the LU decomposition and forward/backward substitution of the Jacobian matrix or the $\mathrm{Y}$ admittance matrix are no longer necessary for the proposed method. Only the DLF matrix is necessary in solving power flow problem. Therefore, the proposed method can save considerable computation resources and this feature makes the proposed method suitable for online operation.

E. Losses Calculation:

The Real power loss of the line section connecting between buses $\mathrm{i}$ and $\mathrm{i}+1$ is computed as

$P_{R L O S S}(i, i+1)=R_{i, i+1} \frac{P_{i}^{2}+Q_{i}^{2}}{\left\|V_{i}\right\|^{2}}$ 
The Reactive power loss of the line section between buses $i$ and $i+1$ is computed as

$$
P_{X L O S S}(i, i+1)=X_{i, i+1} \frac{P_{i}^{2}+Q^{2}}{\left\|V_{i}\right\|^{2}}
$$

The total Real and Reactive power loss of the feeder PrRLoss

is determined by summing up the losses of all sections of the feeder, which is given by:

$$
\begin{aligned}
& P_{\text {FRLOSS }}(i, i+1)=\sum_{i=1}^{N-1} P_{R L O S S}(i, i+1) \\
& P_{\text {FXLOSS }}(i, i+1)=\sum_{i=1}^{N-1} P_{X L O S S}(i, i+1)
\end{aligned}
$$

\section{IV}

\section{Particle Swarm Optimization}

Particle Swarm Optimization (PSO) is a Meta heuristic parallel search technique used for optimization of continues nonlinear problems. PSO has roots in two main component methodologies perhaps more obvious are ties to artificial life. It is also related, however to evolutionary computation and has ties to both genetic algorithms and evolutionary programming. It requires only primitive mathematical operators, and is computationally inexpensive in terms of both memory requirements and speed. It conducts searches using a population of particles, corresponding to individuals. Each particle represents a Candidate solution to the capacitor sizing problem. In a PSO system, particles change their positions by flying around a multi-dimensional search space until a relatively unchanged position has been encountered, or until computational limits are exceeded. The general elements of the PSO are briefly explained as follows:

Particle $\mathrm{X}(\mathrm{t})$ : It is a k-dimensional real valued vector which represents the candidate solution. For an ith particle at a time $\mathrm{t}$, the particle is described as $\mathrm{X}_{\mathrm{i}}(\mathrm{t})=\left\{\mathrm{X}_{\mathrm{i}}, 1(\mathrm{t}), \mathrm{X}_{\mathrm{i}}, 2(\mathrm{t}), \ldots \mathrm{X}_{\mathrm{i}}, \mathrm{k}(\mathrm{t})\right\}$.

Population: It is a set of ' $n$ ' number of particles at a time $t$ described as $\left\{X_{1}(t), X_{2}(t) \ldots X_{n}(t)\right\}$.

Swarm: It is an apparently disorganized population of moving particles that tend to cluster together while each particle seems to be moving in random direction.

Particle Velocity $\mathrm{V}(\mathrm{t})$ : It is the velocity of the moving particle represented by a k-dimensional real valued vector $\mathrm{V}_{\mathrm{i}}(\mathrm{t})=\left\{\mathrm{v}_{\mathrm{i}}, 1(\mathrm{t}), \mathrm{v}_{\mathrm{i}}, 2(\mathrm{t}) \ldots \ldots \mathrm{v}_{\mathrm{i}}, \mathrm{k}(\mathrm{t})\right\}$.

Inertia weight $\mathrm{W}(\mathrm{t})$ : It is a control parameter that is used to control the impact of the previous velocity on the current velocity.

Particle Best (pbest): Conceptually pbest resembles autobiographical memory, as each particle remembers its own experience. When a particle moves through the search space, it compares its fitness value at the current position to the best

value it has ever attained at any time up to the current time. The best position that is associated with the best fitness arrived so far is termed as individual best or Particle best. For each Particle in the swarm its pbest can be determined and updated during the search.

Global Best (gbest): It is the best position among all the individual pbest of the particles achieved so far.

Velocity Updation: Using the global best and individual best, the ith particle velocity in kth dimension is updated according to the following equation.

$\mathrm{V}[\mathrm{i}][\mathrm{j}]=\mathrm{K} *\left(\mathrm{w}^{*} \mathrm{v}[\mathrm{i}][\mathrm{j}]+\mathrm{c} 1 *\right.$ rand $1 *(\operatorname{pbest} \mathrm{X}[\mathrm{i}][\mathrm{j}]-\mathrm{X}[\mathrm{i}][\mathrm{j}])+$

c2*rand $2 *$ (gbestX[j]-X[i][j])).

Where, $\mathrm{K}$ constriction factor, c1, c2 weight factors, w Inertia weight parameter, i particle number, $\mathrm{j}$ control variable, rand 1 , rand 2 random numbers between 0 and 1

Stopping criteria: This is the condition to terminate the search process. It can be achieved either of the two following methods:

i. The number of the iterations since the last change of the best solution is greater than a pre-specified number.

ii. The number of iterations reaches a pre specified maximum

value.

\section{Algorithm for Pso}

Step1: Run the base case distribution load flow and determine the active power loss.

Step2: Identify the candidate buses for placement capacitor.

Step 3:Generate randomly ' $n$ ' number of particles where each particle is represented as particle[i][17] $\{\mathrm{Qc1}, \mathrm{Qc2}, \ldots \ldots \ldots . \mathrm{Qcj}\}$

Step 4: Run the load flow by placing a particle ' $\mathrm{i}$ ' at the candidate bus for reactive power compensation and store the active power loss (TLP).

Step 5: Evaluate the fitness value. If the current fitness value is greater than the its pbest value, then assign the pbest value to the current value.

Step6: Determine the current global best (g_best_particles) minimum among the particles individual best (pbest) values. 
Step 7: Compare the global position with previous. If the current position is greater than the previous, then set the global position to the current global position.

Step 8: update the particle velocity by using V[i][j] $=K *\left(w^{*} v[i][j]+c 1 *\right.$ rand $1 *(p b e s t X[i][j]-X[i][j])+$

c2*rand $2 *($ gbestX[j]-X[i][j])).

Step 9: Update the position of particle by adding the velocity v[i][j].

Step 10: Now run the load flow and determine the active power loss (pl) with the updated particle.

Step 11: Repeat step 5 to 7

Step 12: Repeat the same procedure for each particle from step 4 to step 7.

\section{Reliability Indices}

System Average Interruption Duration Index (SAIDI)

The most often used performance measurement for a sustained interruption is the System Average Interruption Duration Index (SAIDI). This index measures the total duration of an interruption for the average customer during a given period. SAIDI is normally calculated on either monthly or yearly basis; however, it can also be calculated daily, or for any other period.

$S A I D I=\frac{\text { Sumofcustomer int erruptionduration }}{\text { Tota } \ln \text { umberofcustomers }} \frac{\sum U_{i}^{*} \lambda}{\sum N_{i}}$

Where $\mathrm{U}_{\mathrm{i}}=$ Annual outage time, Minutes,

$\mathrm{N}_{\mathrm{i}}=$ Total Number of customers of load point $\mathrm{i}$.

SAIDI is measured in units of time, often minutes or hours. It is usually measured over the course of a year, and according to IEEE Standard 1366-1998 the median value for North American utilities is approximately 1.50 hours.

Customer Average Interruption Duration Index (CAIDI)

Once an outage occurs the average time to restore service is found from the Customer Average Interruption Duration Index (CAIDI). CAIDI is calculated similar to SAIDI except that the denominator is the number of customers interrupted versus the total number of utility customers. CAIDI is,

$\mathrm{CAIDI}=\frac{\text { Sum of customer interruptions durations }}{\text { Total number of customers interrupptions }}=\frac{\sum U_{i} * N_{i}}{\sum \lambda_{i} * N_{I}} \cdot$

Rate.

Where $\mathrm{U}_{\mathrm{i}}=$ Annual outage time, Minutes, $\mathrm{N}_{\mathrm{i}}=$ Total Number of customers of load point i., $\lambda_{\mathrm{i}}=$ Failure

CAIDI is measured in units of time, often minutes or hours. It is usually measured over the course of a year, and according to IEEE Standard 1366-1998 the median value for North American utilities is approximately 1.36 hours

\section{System Average Interruption Frequency Index (SAIFI)}

The System Average Interruption Frequency Index (SAIFI) is the average number of time that a system customer experiences an outage during the year (or time period under study). It is usually measured over the course of a year, and according to IEEE Standard 1366-1998 the median value for North American utilities is approximately 1.10 interruptions per customer.

$$
\begin{aligned}
& \mathrm{SAIFI}=\frac{\text { Total number } \text { of customer interuptions }}{\text { Total number of customers served }}=\frac{\sum \lambda_{i} * N_{i}}{\sum N_{I}} \\
& \text { SAIFI }=\frac{\text { SAIDI }}{\text { CAIDI }}
\end{aligned}
$$

Where $\mathrm{N}_{\mathrm{i}}=$ Total Number of customers interrupted.

$\lambda_{\mathrm{i}}=$ Failure Rate.

\section{Average Service Availability Index (ASAI)}

This is sometimes called the service reliability index. The ASAI is usually calculated on either a monthly basis ( 730 hours) or a yearly basis $(8,760$ hours), but can be calculated for any time period. The ASAI is found as,

$$
\begin{aligned}
& A S A I=\left[1-\left(\frac{\sum\left(r_{i}^{*} N_{i}\right)}{\left(N_{T} * T\right)}\right)\right]^{*} 100 \\
& A S U I=1-A S A I
\end{aligned}
$$

Where $\mathrm{T}=$ Time period under study, hours. $\mathrm{r}_{\mathrm{i}}=$ Restoration Time, Minutes, $\mathrm{N}_{\mathrm{i}}=$ Total Number of customers interrupted.

$\mathrm{N}_{\mathrm{T}}=$ Total Customers served. 
Average Energy Not Supplied (AENS)

This is also called as Average System Curtailment Index (ASCI)

AENS $=\frac{\text { Totalenergynot sup plied }}{\text { Tota } \ln \text { umberofcustomersserved }}=\frac{\sum L_{a(i)} * U(i)}{\sum N_{i}}$

VII. Investigated REAL TIME SYSTEM \&RESULTS

In this paper real time radial feeder is considered, UPADHYA NAGAR urban feeder located at $33 \mathrm{Kv}$ MANGALAM substation in Tirupati, Chittoor (Dt.), Andhra Pradesh, India. It is an fast growing residential area shown in figure 2.

Real time radial feeder system data

The radial distribution systems have following characteristics

Base Voltage $=11 \mathrm{KV}$. Base MVA=100.

Conductor type $=$ All Aluminum Alloy Conductor $(\mathrm{AAAC})$

Resistance $=0.55 \mathrm{ohm} / \mathrm{KM}$., Reactance $=0.351 \mathrm{ohm} / \mathrm{KM}$.

A software program was developed in MATLAB for Load flow solution and PSO is used for placement of capacitor to analyze the results for Radial Distribution feeder. To understand the effectives of the method, a 42-node $11 \mathrm{kV}$ Upadhayan urban feeder is selected. Line data for this feeder is shown in Table I. Throughout day Load is not constant; it varies from time to time. By considering the terms Diversity factor and Power Factor, five deferent conditions are considered. 1. Average DF Good PF, 2. High DF High PF, 3.High DF Low PF, 4. Low DF High PF, 5.Low DF low PF 6. Average DF Poor PF 7. Unity DF Low PF .Generally a feeder that occurs with Average DF Good PF where Average DF is 0.40 and Good PF is 0.93 . When the load is high (High DF) and the PF is also high (High PF), this condition does not occur in the day but for the analysis only it considered. When the load is high (High DF), the PF decreases (Low PF), this condition occurs during the peak demand. When the load in Low (Low DF) then the PF is high (High PF), this condition occurs during the light load conditions. Low DF and Low PF condition does not occur in the day. This condition is assumed for analysis purpose only. The load flow solution obtained is used to know bus voltages profiles for 7 conditions which are shown in below figure 3 and losses in Table II. This Upadhayanagar feeder is not installed by any capacitor bank at LT side. Without installation also there are no nodes having voltages less than 0.95 p.u. So there is no need of capacitor placement for above five conditions.

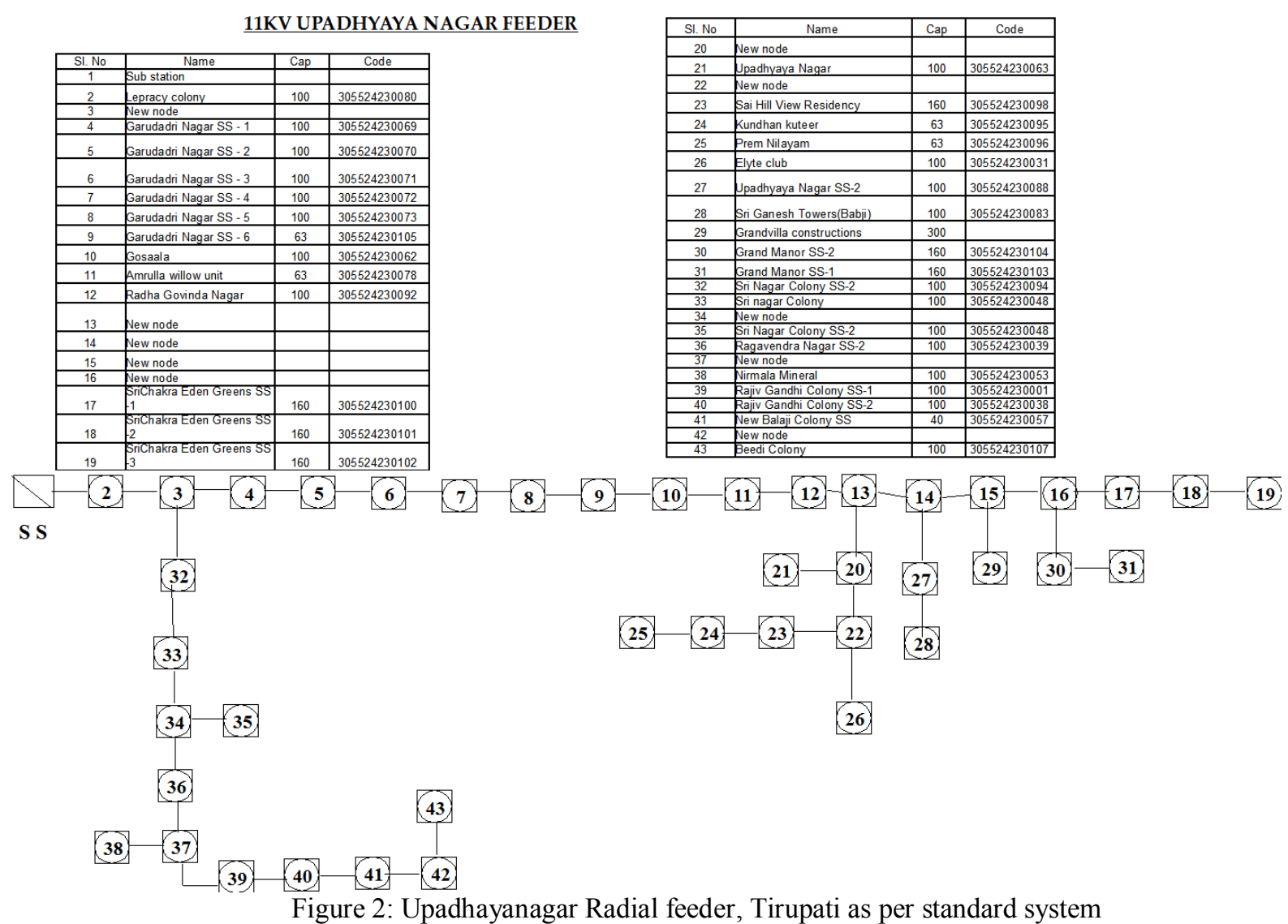


Table I Line data of Upadhayanagar Feeder, Tirupati

\begin{tabular}{|c|c|c|c|c|c|}
\hline Bus No & From Node & To Node & Distance (KM) & $\mathrm{R} \Omega$ & $\mathrm{X} \Omega$ \\
\hline 1 & 1 & 2 & 0.1 & 0.055 & 0.0351 \\
\hline 2 & 2 & 3 & 0.3 & 0.165 & 0.1053 \\
\hline 3 & 2 & 4 & 0.2 & 0.11 & 0.0702 \\
\hline 4 & 4 & 5 & 0.2 & 0.11 & 0.0702 \\
\hline 5 & 5 & 6 & 0.2 & 0.11 & 0.0702 \\
\hline 6 & 6 & 7 & 0.2 & 0.11 & 0.0702 \\
\hline 7 & 7 & 8 & 0.2 & 0.11 & 0.0702 \\
\hline 8 & 8 & 9 & 0.4 & 0.22 & 0.1404 \\
\hline 9 & 9 & 10 & 0.4 & 0.22 & 0.1404 \\
\hline 10 & 10 & 11 & 0.1 & 0.055 & 0.0351 \\
\hline 11 & 11 & 12 & 0.3 & 0.165 & 0.1053 \\
\hline 12 & 12 & 13 & 0.3 & 0.165 & 0.1053 \\
\hline 13 & 13 & 20 & 0.2 & 0.11 & 0.0702 \\
\hline 14 & 20 & 21 & 0.1 & 0.055 & 0.0351 \\
\hline 15 & 20 & 22 & 0.1 & 0.055 & 0.0351 \\
\hline 16 & 22 & 23 & 0.1 & 0.055 & 0.0351 \\
\hline 17 & 23 & 24 & 0.2 & 0.11 & 0.0702 \\
\hline 18 & 24 & 25 & 0.3 & 0.165 & 0.1053 \\
\hline 19 & 22 & 26 & 0.2 & 0.11 & 0.0702 \\
\hline 20 & 13 & 14 & 0.3 & 0.165 & 0.1053 \\
\hline 21 & 14 & 27 & 0.2 & 0.11 & 0.0702 \\
\hline 22 & 27 & 28 & 0.2 & 0.11 & 0.0702 \\
\hline 23 & 14 & 15 & 0.1 & 0.055 & 0.0351 \\
\hline 24 & 15 & 29 & 0.2 & 0.11 & 0.0702 \\
\hline 25 & 15 & 16 & 0.3 & 0.165 & 0.1053 \\
\hline 26 & 16 & 30 & 0.1 & 0.055 & 0.0351 \\
\hline 27 & 30 & 31 & 0.1 & 0.055 & 0.0351 \\
\hline 28 & 16 & 17 & 0.1 & 0.055 & 0.0351 \\
\hline 29 & 17 & 18 & 0.3 & 0.165 & 0.1053 \\
\hline 30 & 18 & 19 & 0.1 & 0.055 & 0.0351 \\
\hline 31 & 3 & 32 & 0.1 & 0.055 & 0.0351 \\
\hline 32 & 32 & 33 & 0.4 & 0.22 & 0.1404 \\
\hline 33 & 33 & 34 & 0.2 & 0.11 & 0.0702 \\
\hline 34 & 34 & 35 & 0.1 & 0.055 & 0.0351 \\
\hline 35 & 34 & 36 & 0.1 & 0.055 & 0.0351 \\
\hline 36 & 36 & 37 & 0.4 & 0.22 & 0.1404 \\
\hline 37 & 37 & 38 & 0.1 & 0.055 & 0.0351 \\
\hline 38 & 37 & 39 & 0.5 & 0.275 & 0.1755 \\
\hline 39 & 39 & 40 & 0.2 & 0.11 & 0.0702 \\
\hline 40 & 40 & 41 & 0.2 & 0.11 & 0.0702 \\
\hline 41 & 41 & 42 & 0.2 & 0.11 & 0.0702 \\
\hline 42 & 42 & 43 & 0.1 & 0.055 & 0.0351 \\
\hline
\end{tabular}

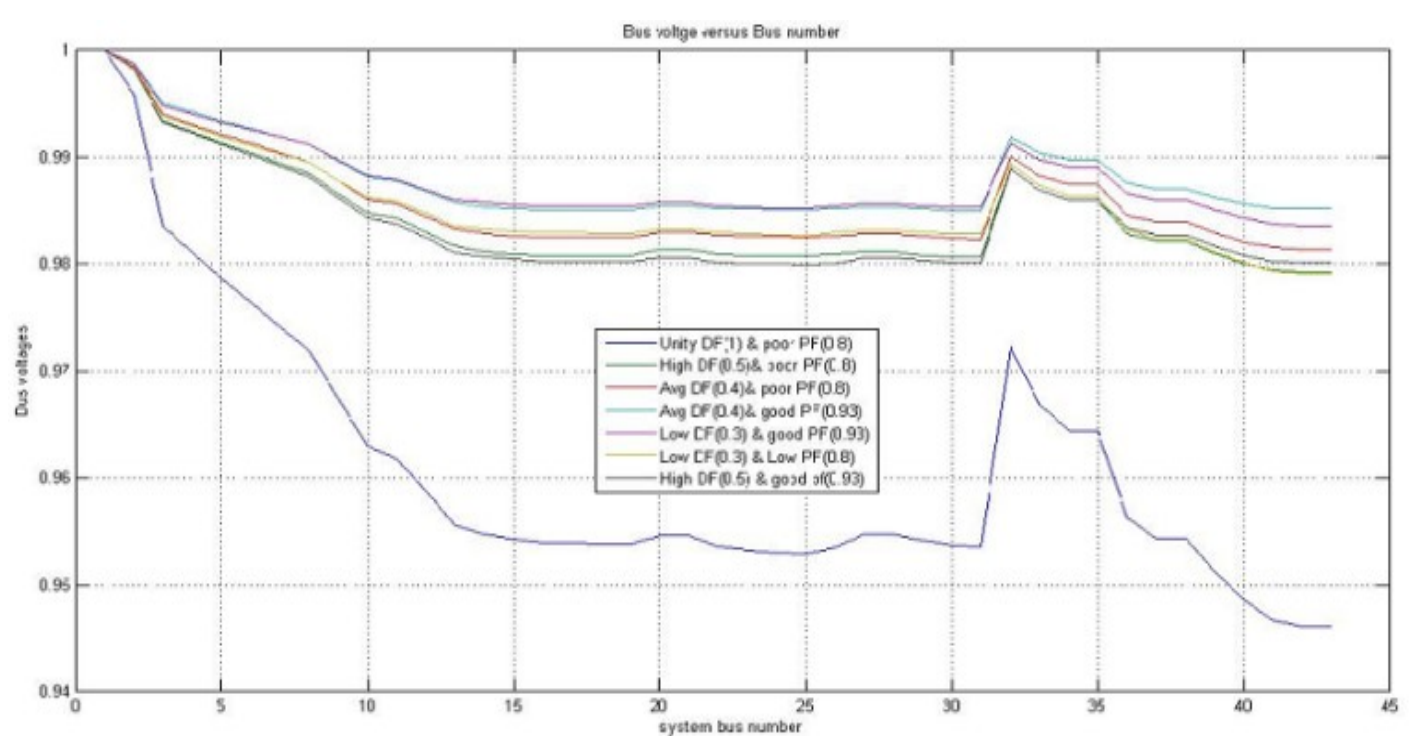

Figure 3: bus voltage for different conditions by BIBC \& BCBV method 


\section{Bus Voltage Sensitivity Index (BVSI):}

Load flow with capacitor capacity of $15 \%$ of the total feeder loading capacity is carried out to find BVSI at various buses using (20). Figure 4 shows the variation of VSI at various buses. As seen from this Figure 5.4, bus number 17 is having the lowest BVSI value of 0.2639 . Therefore, bus 17 is considered as the candidate bus for the capacitor placement.

$$
\text { BVSI }_{i}=\sqrt{\frac{\sum_{i=1}^{n}\left(1-\nabla_{2}\right)^{2}}{a}}
$$

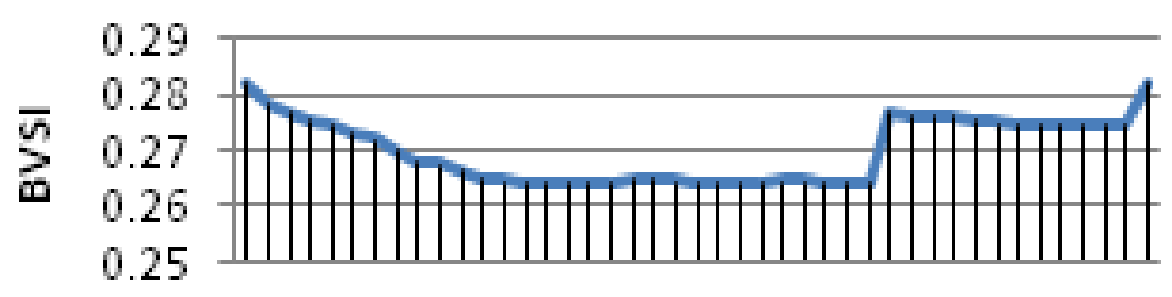

\section{3}

\section{Bus number}

Figure 4: bus Variation of BVSI with bus number.

The results shows that following buses are sensitive bus voltages $(<0.95 \mathrm{pu}) 36,37,38,39,40,41$ and 42 and are instable bus voltages, that can be improved by placing capacitor at single node or by placing capacitor at multiple nodes. By using Particle Swarm Optimization Technique (Section V). Multiple placed capacitors have higher voltages profiles than the single placement shown figure 4 . The results for power losses are shown in table III for before and after placement of capacitor. These losses are compared with losses obtained by using load flow and energy consumption method. Energy losses are computed for Updahayanagar feeder by real time energy consumed data by the feeder from substation. It is observed that the computed energy losses closely match with the calculated energy (real time data) losses

Table II: Losses at different conditions

\begin{tabular}{|c|l|l|l|}
\hline Conditions & \multicolumn{1}{|c|}{$\begin{array}{c}\text { Real Power } \\
\text { losses } \\
(\mathbf{K W})\end{array}$} & $\begin{array}{c}\text { Reactive Power } \\
\text { losses } \\
(\mathbf{K W})\end{array}$ & $\begin{array}{c}\text { Total } \\
\text { Losses } \\
(\mathbf{K W})\end{array}$ \\
\hline Avg DF Poor PF & 37.2237 & 23.7555 & 60.9791 \\
\hline AVG DF Good PF & 25.6313 & 16.3574 & 41.9887 \\
\hline High DF Good PF & 45.9267 & 29.3096 & 75.2362 \\
\hline High DF Poor DF & 48.0106 & 30.6395 & 78.6501 \\
\hline Low DF Good PF & 28.4457 & 18.1536 & 46.5993 \\
\hline Low DF Poor DF & 42.3634 & 27.0355 & 69.3989 \\
\hline Unity DF Poor PF & 296.6474 & 189.315 & 485.9624 \\
\hline
\end{tabular}

Table III: Power loss of the feeder before and after compensation

\begin{tabular}{|c|c|}
\hline Single Placement of capacitor & Multiple Placement of Capacitor \\
\hline $\mathrm{Q}_{\text {L loss }}=189.315 \mathrm{KVAR}$ & $\mathrm{Q}_{-}$loss $=152.8818 \mathrm{KVAR}$ \\
\hline $\mathrm{P} \quad$ loss $=296.6474 \mathrm{KW}$ & $\mathrm{P} \_$loss $=239.5584 \mathrm{KW}$ \\
\hline MIN_V=0.9462 & MIN_V=0.9462 \\
\hline Rank $=36,37,38,39,4041,42,43$ & Rank $=36,37,38,39,4041,42,43$ \\
\hline \multicolumn{2}{|c|}{ After Compensation } \\
\hline $\mathrm{Q}_{\text {_l loss }}=133.4080 \mathrm{KVAR}$ & $\mathrm{Q}_{-}$loss $=123.9763 \mathrm{KVAR}$ \\
\hline $\mathrm{P} \_$loss $=209.0438 \mathrm{KW}$ & $\mathrm{P} \_$loss $=194.2649 \mathrm{KW}$ \\
\hline MIN_V=0.9634 & MIN_V=0.9634 \\
\hline Rank $=0$ & Rank $=0$ \\
\hline
\end{tabular}




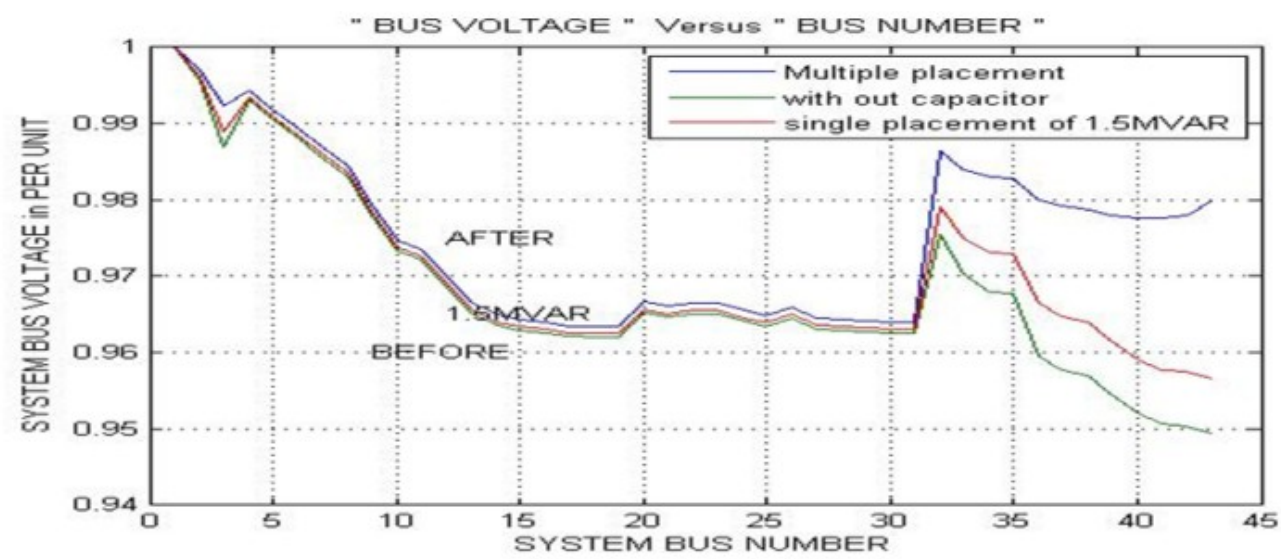

Figure 5: Voltage profiles for before, after capacitors placement using PSO.

Table IV Injected Reactive Power using PSO at different nodes

\begin{tabular}{|l|l|l|}
\hline \multicolumn{2}{|l|}{ Nodes Compensated } & 36,38 \\
\hline Best Node $=36$ & Best Particle & -1344.9 KVAR \\
\hline Best Node $=38$ & Best Particle & -880.5 KVAR \\
\hline Total Injected Reactive Power & -2225.4 KVAR \\
\hline
\end{tabular}

Table IV represents the compensated nodes after placing capacitor at single and multiple nodes. Table $\mathrm{V}$ represents the losses calculated as per substation and using mat lab.

Table V. Power loss calculation by using load flow method

\begin{tabular}{|r|r|l|}
\hline \multicolumn{4}{|c|}{ Upadyayanagar Feeder } \\
\hline BIBC and BCBV Method \\
\hline Avg. DF Gud. PF \\
\hline TLP $=$ & 25.6313 & KW \\
\hline TLQ $=$ & 16.3574 & KVAR \\
\hline TL $=$ & 41.9887 & KW \\
\hline \multicolumn{4}{|c|}{$=$} & 3.72 & $\%$ \\
\hline Energy Loss $=($ TLP*24*31) & 19067.7 & Units \\
\hline $\begin{array}{l}\text { Energy Loss as per PPL Sheet }=3.72 \% \text { of } 512330= \\
\text { Units }\end{array}$ \\
\hline
\end{tabular}

The details of the distribution system are shown in Table VI. There are 5 interruption cases during the year 2012-2013. (Table VII). When the feeder was not provided with isolators, all load points got affected during the 5 interruptions. The Distribution System Reliability Indices are calculated by using section VI and the results are tabulated in IX. When the feeder is provided with isolator at $13^{\text {th }}$ node, the load point 13 will only be affected and the number of load points affected is reduced from 43 to 35 during 5 interruption cases. Distribution Reliability Indices are shown in Table IX. The percentage of indices is represented in pie chart as shown in Figure 7 with and without isolator. When the feeder is not provided with isolator the Average Energy Not Supplied (AENS) is $2.272 \mathrm{KWh} /$ Customer. When the feeder is provided with isolator at $13^{\text {th }}$ node the Average Energy Not Supplied (AENS) is reduced to $1.272 \mathrm{KWh} /$ Customer

Table VI Details of Distribution System

\begin{tabular}{|c|c|c|c|}
\hline S.NO & $\begin{array}{c}\text { No. of } \\
\text { Customers }\end{array}$ & $\begin{array}{c}\text { P } \\
\text { (KW) }\end{array}$ & $\begin{array}{c}\text { Avg. } \\
\text { Load }\end{array}$ \\
\hline 1 & 0 & 0.00 & 0.00 \\
\hline 2 & 120 & 106.00 & 0.88 \\
\hline 3 & 0 & 0.00 & 0.00 \\
\hline 4 & 179 & 151.00 & 0.84 \\
\hline 5 & 1 & 2.00 & 2.00 \\
\hline 6 & 1 & 2.00 & 2.00 \\
\hline 7 & 1 & 2.00 & 2.00 \\
\hline 8 & 1 & 2.00 & 2.00 \\
\hline 9 & 76 & 86.00 & 1.13 \\
\hline 10 & 15 & 30.00 & 2.00 \\
\hline 11 & 0 & 0.00 & 0.00 \\
\hline 12 & 50 & 75.00 & 1.50 \\
\hline 13 & 0 & 0.00 & 0.00 \\
\hline
\end{tabular}




\begin{tabular}{|c|c|c|c|}
\hline 14 & 0 & 0.00 & 0.00 \\
\hline 15 & 0 & 0.00 & 0.00 \\
\hline 16 & 0 & 0.00 & 0.00 \\
\hline 17 & 12 & 84.00 & 7.00 \\
\hline 18 & 1 & 2.00 & 2.00 \\
\hline 19 & 1 & 2.00 & 2.00 \\
\hline 20 & 0 & 0.00 & 0.00 \\
\hline 21 & 113 & 391.00 & 3.46 \\
\hline 22 & 0 & 0.00 & 0.00 \\
\hline 23 & 60 & 150.00 & 2.50 \\
\hline 24 & 8 & 50.00 & 6.25 \\
\hline 25 & 10 & 60.00 & 6.00 \\
\hline 26 & 41 & 87.00 & 2.12 \\
\hline 27 & 3 & 6.00 & 2.00 \\
\hline 28 & 15 & 85.00 & 5.67 \\
\hline 29 & 1 & 300.00 & 300.00 \\
\hline 30 & 16 & 100.00 & 6.25 \\
\hline 31 & 36 & 220.00 & 6.11 \\
\hline 32 & 218 & 416.00 & 1.91 \\
\hline 33 & 218 & 416.00 & 1.91 \\
\hline 34 & 0 & 0.00 & 0.00 \\
\hline 35 & 138 & 191.00 & 1.38 \\
\hline 36 & 409 & 564.00 & 1.38 \\
\hline 37 & 0 & 0.00 & 0.00 \\
\hline 38 & 138 & 191.00 & 1.38 \\
\hline 39 & 489 & 578.00 & 1.18 \\
\hline 40 & 490 & 571.00 & 1.17 \\
\hline 41 & 426 & 543.00 & 1.27 \\
\hline 42 & 0 & 0.00 & 0.00 \\
\hline \multirow[t]{2}{*}{43} & 214 & 319.00 & 1.49 \\
\hline & 3501 & 5782.00 & \\
\hline
\end{tabular}

Interruption data

Table VII Interruption effect in a calendar year (without isolator)

\begin{tabular}{|c|c|c|c|}
\hline $\begin{array}{l}\text { Interruption } \\
\text { Case }\end{array}$ & $\begin{array}{l}\text { Load Point } \\
\text { Affected }\end{array}$ & $\begin{array}{c}\text { Duration } \\
\text { (hrs) }\end{array}$ & Cause of Interruption \\
\hline \multirow[t]{2}{*}{1} & \multirow[t]{2}{*}{$\begin{array}{l}\text { All load points get } \\
\text { affected }\end{array}$} & 0.52 & $\begin{array}{l}\text { Line clearence for Transformer } \\
\text { maintaince }\end{array}$ \\
\hline & & 1.35 & $\begin{array}{l}\text { Main supply failed due to Distribution } \\
\text { line damage }\end{array}$ \\
\hline \multirow[t]{3}{*}{2} & \multirow{3}{*}{$\begin{array}{l}\text { All load points get } \\
\text { affected }\end{array}$} & 0.15 & Fault in distribution line \\
\hline & & 1.15 & $\begin{array}{l}\text { Line clearance for Transformer } \\
\text { erraction }\end{array}$ \\
\hline & & 0.25 & main supply failed due to line Fault \\
\hline \multirow[t]{3}{*}{3} & \multirow{3}{*}{$\begin{array}{l}\text { All load points get } \\
\text { affected }\end{array}$} & 3.00 & Trip due to environmental conditions \\
\hline & & 0.20 & main supply failed due to fault \\
\hline & & 3.50 & $\begin{array}{l}\text { Load shut for general maintaince in the } \\
\text { feeder }\end{array}$ \\
\hline 4 & $\begin{array}{l}\text { All load points get } \\
\text { affected }\end{array}$ & 0.30 & main supply failed due to fault \\
\hline \multirow[t]{3}{*}{5} & $\begin{array}{l}\text { All load points get } \\
\text { affected }\end{array}$ & 6.00 & $\begin{array}{l}\text { Three line clearances for erraction of } \\
\text { new transformers }\end{array}$ \\
\hline & $\begin{array}{c}\text { All load points get } \\
\text { affected }\end{array}$ & 0.45 & main supply failed due to fault 4 no's \\
\hline & $\begin{array}{l}\text { All load points get } \\
\text { affected }\end{array}$ & 2.25 & Line break down due to fault 2 no's \\
\hline
\end{tabular}


Table VIII Interruption effect in a calendar year (with isolator)

\begin{tabular}{|c|c|c|c|}
\hline $\begin{array}{l}\text { Interruption } \\
\text { Case }\end{array}$ & Load Point Affected & $\begin{array}{l}\text { Duration } \\
\text { (hrs) }\end{array}$ & Cause of Interruption \\
\hline \multirow[t]{2}{*}{1} & \multirow{2}{*}{$\begin{array}{c}14,15,16,17,18,19,20, \\
21,22,23,24,25,26,27, \\
28,29,30,31\end{array}$} & 0.52 & $\begin{array}{l}\text { Line clearance for Transformer } \\
\text { maintaince }\end{array}$ \\
\hline & & 1.35 & $\begin{array}{l}\text { Main supply failed due to } \\
\text { Distribution line damage }\end{array}$ \\
\hline \multirow[t]{3}{*}{2} & \multirow{3}{*}{$\begin{array}{c}14,15,16,17,18,19,20 \\
21,22,23,24,25,26,27 \\
28,29,30,31\end{array}$} & 0.15 & Fault in distribution line \\
\hline & & 1.15 & $\begin{array}{l}\text { Line clearence for Transformer } \\
\text { erraction }\end{array}$ \\
\hline & & 0.25 & $\begin{array}{l}\text { main supply failed due to line } \\
\text { Fault }\end{array}$ \\
\hline \multirow[t]{3}{*}{3} & \multirow{3}{*}{$\begin{array}{c}14,15,16,17,18,19,20, \\
21,22,23,24,25,26,27, \\
28,29,30,31\end{array}$} & 3.00 & $\begin{array}{l}\text { Trip due to environmental } \\
\text { conditions }\end{array}$ \\
\hline & & 0.20 & main supply failed due to fault \\
\hline & & 3.50 & $\begin{array}{l}\text { Load shut for general maintaince } \\
\text { in the feeder }\end{array}$ \\
\hline 4 & $\begin{array}{c}14,15,16,17,18,19,20 \\
21,22,23,24,25,26,27, \\
28,29,30,31\end{array}$ & 0.30 & main supply failed due to fault \\
\hline \multirow[t]{3}{*}{5} & $\begin{array}{c}14,15,16,17,18,19,20 \\
21,22,23,24,25,26,27 \\
28,29,30,32\end{array}$ & 6.00 & $\begin{array}{l}\text { Three line clearances for } \\
\text { erraction of new transformers }\end{array}$ \\
\hline & $\begin{array}{c}14,15,16,17,18,19,20 \\
21,22,23,24,25,26,27 \\
28,29,30,33\end{array}$ & 0.45 & $\begin{array}{l}\text { main supply failed due to fault } 4 \\
\text { no's }\end{array}$ \\
\hline & $\begin{array}{c}14,15,16,17,18,19,20 \\
21,22,23,24,25,26,27, \\
28,29,30,34\end{array}$ & 2.25 & $\begin{array}{c}\text { Line break down due to fault } 2 \\
\text { no's }\end{array}$ \\
\hline
\end{tabular}

Table IX Distribution system Reliability Indices with without Isolator

\begin{tabular}{|l|l|l|}
\hline ndices & \multicolumn{1}{|c|}{ Without isolator } & \multicolumn{1}{c|}{ With isolator } \\
\hline AIFI & 5.000 interruptions/customer & 1.075 interruptions/customer \\
\hline AIDI & $21 \mathrm{hrs} /$ customer & $4.517 \mathrm{hrs} /$ customer \\
\hline AIDI & $4.2 \mathrm{hrs} /$ customer interruption & $4.2 \mathrm{hrs} /$ customer interruption \\
\hline SAI & 0.9976 & 0.99948 \\
\hline SUI & 0.002397 & 0.000516 \\
\hline ENS & $2.272 \mathrm{KWh} /$ customer & $1.272 \mathrm{KWh} /$ customer \\
\hline
\end{tabular}
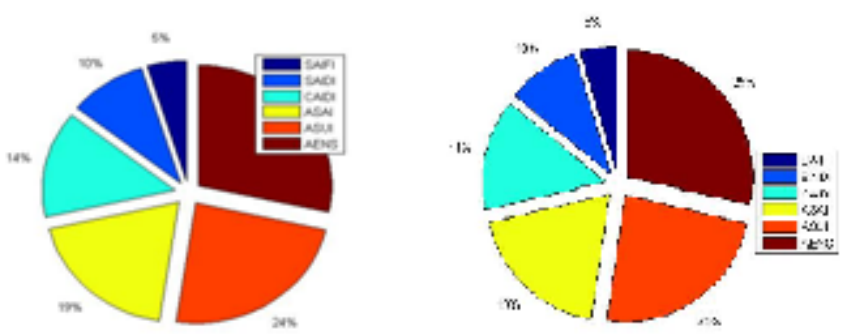

Figure 6.Indices representation in pie chart with and without isolator

\section{Conclusion}

The radial distribution $11 \mathrm{Kv}$ Upadyanagar feeder is applied with load flow and the feeble voltage profiles are identified and those nodes are proposed for capacitor placement using particle swarm optimization technique. The voltages profiles and losses before and after compensation using PSO for single and multiple 
placement of capacitor, the voltage profiles get improved and losses get reduced. Distribution system Reliability indices are evaluated for the feeder and results are presented. It is concluded that by providing more isolators in the radial feeder we can reduce the Average Energy Not Supplied (AENS) to the customers their by improves the continuity of power supply

\section{References}

[1] Ramanjaneyulu Reddy P, N.M.G.Kumar, P.Sangamshwara Raju, "Load flow based reliability assessment of a real time radial distribution system - case study" UNIASCIT, Vol2(3), 2012, 292-300.

[2] K.Prakash, M.Sydulu, "Partical Swarm Optimization Based Capacitor Placement on Radial Distribution System" ,Power Engineering Society, IEEE General Meeting - PES , pp. 1-5, 2007

[3] S.Sivanagaraju, J.Viswanatha Rao, M.Gridhar, "A Loop based load flow method for weakly meshed distribution network" , ARPN Journal of Engg. and Applied Sciences, Vol 3 No 4, 2008.

[4] A.A.A. Esmin and G. Lambert-Torres, "A Particle Swarm Optimization Applied to Loss Power Minimization”, IEEE Transactions on Power Systems, USA, vol. 20, no. 2, pp. 859-866, 2005.

[5] S. Ghosh and D. Das, "Method for load-flow solution of radial distribution Networks", IEEE Proceedings on Generation, Transmission \& Distribution, Vol.146, No. 6, pp. 641-648, 1999

[6] Turan Gonen "Electric power distribution system Engineering" ${ }^{\text {ed }}$ edition, CRC press by 2008

[7] K. A. Birt, J. J. Graffy, J. D. McDonald, and A. H. El-Abiad, “Three phase load flow program,” IEEE Trans. Power Apparat. Syst., vol. PAS.95, pp. 59-65, Jan./Feb. 1976.

[8] D. Shirmohammadi, H. W. Hong,et.al "A compensation- based power flow method for weakly meshed distribution and transmission networks," IEEE Trans. Power Syst., vol. 3, pp.753-762, May 1988

[9] G. X. Luo and A. Semlyen, "Efficient load flow for large weakly meshed networks," IEEE Trans. Power Syst., vol. 5, pp. 13091316, Nov. 1990.

[10] C. S. Cheng and D. Shirmohammadi, "A three-phase power flow method for real-time distribution system analysis," IEEE Trans. Power Syst., vol. 10, pp. 671-679, May 1995.

[11] W. M. Kersting and L. Willis, "Radial Distribution Test Systems, IEEE Trans. Power Syst.", vol. 6, IEEE Distribution Planning Working Group Rep., Aug. 1991.

[12] M. E Baran and F. F. Wu, "Optimal Sizing of Capacitors Placed on a Radial Distribution System", IEEE Trans. Power Delivery, vol. no.1, pp. 1105-1117, Jan. 1989.

[13] M. E. Baran and F. F. Wu, "Optimal Capacitor Placement on radial distribution system," IEEE Trans. Power Delivery, vol. 4, no.1, pp. 725734, Jan. 1989.

[14] M. H. Haque, "Capacitor placement in radial distribution systems for loss reduction," IEE Proc-Gener, Transm, Distrib, vol, 146, No.5, Sep. 1999.

[15] R.Billinton and J. E. Billinton, “Distribution system reliability indices,IEEE Trans. Power Del., vol. 4, no. 1, pp.561-586, Jan. 1989.

[16] IEEE Standards, "IEEE Guide for Electric Power Distribution Reliability Indices", IEEE Power Engineering Society.

[17] Roy Billinton and Ronald N.Allan, A Text Book on "Reliability Evaluation of Power Systems" $2{ }^{\text {nd }}$ Edition, Plenum Press, New York and London.

Author's detail:

Mr. D.Murali Currently pursuing M.Tech at Sri venkatesa Perumal College of engineering and Technology, Puttur and Obtained his B.Tech in Electrical and Electronics Engineering from JNTU University at Audisankara College, Gudur. His area of interest power systems, operation and control, distribution systems and application of FACTS devices in Transmission systems.

Mr. A.Hema sekhar currently working as Associate Professor \& Head of the Dept. of Electrical and Electronics Engineering, S.V.P.C.E.T,Puttur and Obtained his B.Tech in Electrical and Electronics Engineering from JNTU,Hyderabad, at Sree Vidyaniketan Engineering College, Rangampet; M.Tech (PSOC) from the S.V.University college of Engineering,Tirupati. His area of interest power systems, operation and control, distribution systems, electrical machines and Power System Stability. 